\title{
OPTICAL MEASUREMENTS FOR LABORATORY OBSERVATIONS OF TSUNAMI RUN-UP ON CONICAL ISLANDS
}

\author{
Peter Rivera, University of Puerto Rico at Mayagüez, peter.rivera6@upr.edu \\ Adam Keen, University of Southern California, adamkeen@usc.edu \\ Patrick Lynett, University of Southern California, plynett@usc.edu
}

\section{INTRODUCTION}

Recent studies and observations suggest that small islands near the mainland do not offer protection against tsunamis and may in fact amplify the run-up. The goal of this study was to better understand how the combined effect of small islands and reefs affects tsunamis runup on a planar beach. Optical measurements were carried out to study the run-up characteristics.

\section{METHODOLOGY}

The study was carried out in the Tsunami Wave Basin at the O.H. Hinsdale Wave Research Laboratory, Oregon State University. Two Panasonic AW-HE60 cameras where used to track run-up on the shore. Through camera calibration we obtain the camera's parameters which are used to undistort the image and obtain reliable run-up measurements. Using a total station ground control points where collected to rectify the images and obtain 'real world coordinates' from the videos. The approach of Rueben et al. (2011) was used to track the wave fronts from the video data.

\section{OUTCOME}

From Figure 2 we can conclude the reef has no effect on the maximum run-up for the s-wave. A very small difference in the maximum run-up for the solitary wave can also be observed. This decrease was not constant and was insignificant in other runs. It is important to point out that for both cases a small decrease $(0.05 \mathrm{~m}-0.2 \mathrm{~m})$ was observed in the run-up around the crest. This difference may seem negligible, but when the run-up is compared in terms of area we can observe an approximate difference of $1 m^{2}-2 m^{2}$. If scaled up to geophysical scales, the difference would be $2.5 \mathrm{~km}^{2}-10 \mathrm{~km}^{2}$.

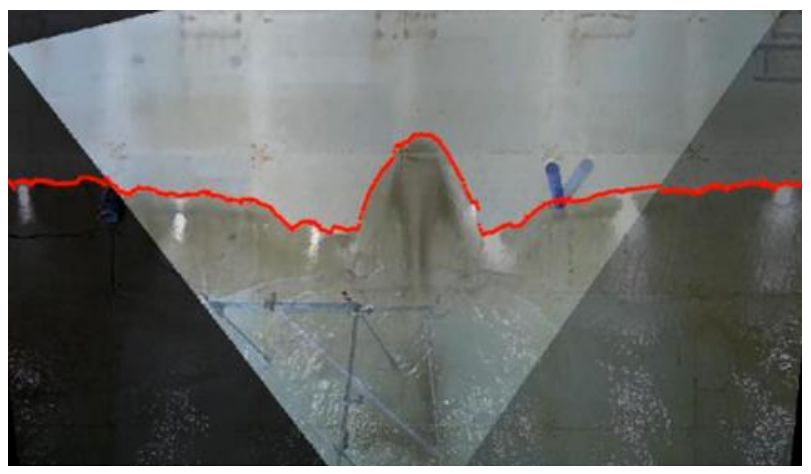

Figure 1. Screen shot of solitary wave from rectified video

\section{FUTURE USAGE}

A deeper analysis must be carried out to determine the exact difference in area and more scenarios should be tested to determine the effectiveness of the reef. The results obtained will serve to improve installation of artificial structures in the nearshore as guards against tsunamis. Another important aspect is the shoreline sheltering coral reefs offer against oceanographic hazards such as tsunamis. With minor adjustments, the methodology to measure run-up could be applied to different scenarios in both laboratory or field.
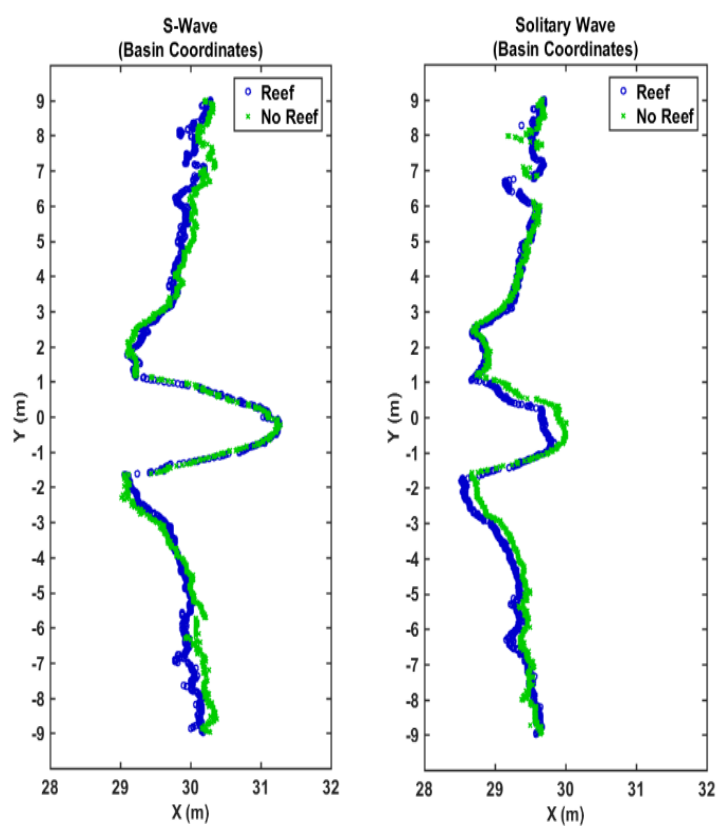

Figure 2. Run-up for s-wave (left) and solitary wave (right)

\section{REFERENCES}

Rueben, M., Holman, R., Cox, D.T., Killian, J., Stanley, J. (2011) "Optical measurements of tsunami inundation through an urban waterfront modeled in a large-scale laboratory basin"

Coastal Engineering, 58(3): 229-238. 